\title{
Prediction of Surface Roughness When Surface Grinding C45 Steel Using CBN Grinding Wheel
}

\author{
Nguyen Van Thien ${ }^{1, *}$, Do Duc Trung', Le Hong $\mathrm{Ky}^{2}$, Le Hoang Anh ${ }^{2}$ \\ ${ }^{1}$ Faculty of Mechanical Engineering, Hanoi University of Industry, Vietnam \\ ${ }^{2}$ Faculty of Mechanical Engineering, Vinh Long University of Technology Education, Vietnam
}

Received December 21, 2019; Revised January 27, 2020; Accepted February 7, 2020

Copyright $\odot 2020$ by authors, all rights reserved. Authors agree that this article remains permanently open access under the terms of the Creative Commons Attribution License 4.0 International License

\begin{abstract}
This paper presents a study of the roughness prediction of the workpiece when using CBN (Cubic Boron Nitride) grinding wheel to process $\mathrm{C} 45$ steel on a surface grinder. On the basis of inheriting the previously published studies on modeling surface roughness of workpiece when grinding, this study was conducted to develop one of these models and build a new model of surface roughness that consider many factors affecting surface roughness. Cutting parameters, parameters of grinding wheel, characteristics of materials, characteristics of contact of grinding wheel with workpiece have been included in the roughness model of the surface roughness of workpiece. This new surface roughness model was used to predict surface roughness of workpiece when grinding $\mathrm{C} 45$ steel with $\mathrm{CBN}$ grinding wheel. The results showed that the surface roughness value when predicting was very suitable for the experiment and the average deviation between the predicted results and the experimental results was only about $9.84 \%$. The surface roughness model proposed in this study also confirms that the roughness can be predicted more accurately than the previous surface roughness models. And then, the development direction for further research is also mentioned in this paper.
\end{abstract}

Keywords Predict Surface Roughness When Grinding, Undeform Chip Thickness, C45 Steel, CBN Grinding Wheel

\section{Introduction}

The roughness of the workpiece surface is a parameter that greatly affects the workability and durability of machine workpieces. When finishing the process of the mechanical products, such as process by grinding, surface roughness is always one of the top criteria to evaluate the efficiency of the machining process. For this reason, a great deal of researches have been done to find solutions for machining a small rough surface. Among them, the empirical research accounts for a large proportion. However, according to studies [1, 2, 3] the cost of experimental research is often expensive, greatly affecting the efficiency of the grinding process. On the other hand, the results of empirical studies are usually only applied to a few specific cases, limiting the scope of applying the research results to actual production. For that reason, there have been several model building studies to predict the surface roughness of workpiece when grinding.

\section{Some Models Predict the surface Roughness of Workpiece When Grinding}

Some predictions of the surface roughness models are models built to show the relationship between surface roughness with machining parameters, technological system parameters and other parameters, based on the theoretical analysis of the cutting process. A number of models have been constructed by several authors with different assumptions summarized in Table 1. 
Table 1. Some models of surface roughness

\begin{tabular}{|c|c|c|c|c|}
\hline No. & Model & Source & Assuming & $\begin{array}{c}\text { Number of } \\
\text { model }\end{array}$ \\
\hline 1 & $R_{a}=0.37 * h_{m}$ & Hecker et al. [3] & $\begin{array}{l}\text { The cross section of the cut created by each abrasive grains left on } \\
\text { the surface workpiece is a triangular shape }\end{array}$ & (1) \\
\hline 2 & $R_{a}=0.423 * h_{m}$ & $\begin{array}{c}\text { Sanjay Agarwal } \\
\text { et al. [4] }\end{array}$ & $\begin{array}{l}\text { The cross-section of scratches of each abrasive grain left on the } \\
\text { surface workpiece is semi-circular shape }\end{array}$ & (2) \\
\hline 3 & $R_{a}=0.396 * h_{m}$ & $\begin{array}{c}\text { Sanjay Agarwal } \\
\text { et al. [5] }\end{array}$ & $\begin{array}{l}\text { The cross section of scratches of each abrasive grain left on the } \\
\text { surface workpiece is parabolic form }\end{array}$ & (3) \\
\hline 4 & $R_{a}=0.471 * h_{m}$ & $\begin{array}{c}\text { Sanchit Kumar } \\
\text { Khare et al. [6] }\end{array}$ & $\begin{array}{l}\text { The cross-section of the scratches of each abrasive brain left on the } \\
\text { surface workpiece is semi-circular shape }\end{array}$ & (4) \\
\hline 5 & $R_{a}=0.92 * h_{m}$ & $\begin{array}{c}\text { Krishna Kumar } \\
\text { Saxena et al. [7] }\end{array}$ & $\begin{array}{l}\text { The cross-section of the scratches of each abrasive brain left on the } \\
\text { surface workpiece is semi-circular shape }\end{array}$ & (5) \\
\hline
\end{tabular}

In the above formulas, $\mathrm{h}_{\mathrm{m}}$ is the undeform chip thickness. The value of $h_{m}$ depends on many parameters such as cutting parameters, grinding wheel type, grain size, etc, and is defined as follows [8]:

$$
h_{m}=2 *\left[v_{w} /\left(N * r * v_{G}\right)\right]^{1 / 2} *\left(t / d_{e}\right)^{1 / 4}
$$

where

$v_{G}$ - The grinding wheel velocity.

$v_{W}$ - The workpiece velocity.

$t$ - The grinding depth.

$d_{e}$ - The equivalent grinding wheel diameter which is determined by Eq. (7)

$$
d_{e}=d_{G} * d_{w} /\left(d_{G} \pm d_{w}\right)
$$

In Eq. (7), the negative sign applies for internal grinding. $d_{G}, d_{W}$ are the grinding wheel diameter and workpiece diameter, respectively. For the surface grinding processes, $d_{W} \rightarrow \infty$, so $d_{e}=d_{G}$.

$r$ - The ratio of the chip width to the thickness, $r=$ $10 \div 20[9,10]$. In this work ' $r$ ' was assumed to be equal to 20 .

$N$ - The is the number of active grits per unit area of wheel's surface. The value of $\mathrm{N}$ is calculated by Eq. (8) [11].

$$
N=4 * f *\left(1 / d_{g}^{2}\right) *\left(4 * \pi / 3 * v_{g}\right)^{-2 / 3}
$$

where

$f$ - The fraction of grinding grains involved in active grinding process, $f=0.5[11,12]$.

$d_{g}$ - The equivalent spherical diameter of grit, is determined by Eq. (9) [1, 2].

$$
d_{g}=15.2 / \mathrm{M}
$$

with $M$ is an indicator of the graininess of the grinding wheel. This is the number of sieve holes per square inch of the sieve.

$v_{g}$ - the volume ratio of the grinding grains in the grinding wheel. The value of $v_{g}$ depends on the structure of the grinding wheel $(S)$. With the common grinding wheel (the structure number is from 0 to 16), the value of $v_{g}$ is determined by Eq. $10[1,2]$. Besides, with the diamond grinding wheel and $\mathrm{CBN}$ grinding wheel, the value of $v_{g}$ is determined according to the sign of the grinding grain concentration as listed in Table 2 [13].

$$
v_{g}(\%)=2 *(32-S)
$$

The data in Table 1 shows, with different assumptions that the surface roughness model also has very different values. Therefore, in each specific processing condition, before using one of those models, it is necessary to have empirical studies to test and select the right model. For example, Do Duc Trung et al. [14] conducted a series of experiments to select the appropriate model for predicting the roughness of surface when grinding. Their results can be summarized as shown in Table 3. However, the results predicting roughness of surface when grinding are still much different from the experimental results. The main reason for the difference between the predicted results and the experimental results is that the expression of the undeform chip thickness has been built in a stationary state without considering the modulus of elasticity of the grinding wheel, the machining materials, the characteristics of contact between grinding wheel and machining materials. Therefore, for the roughness value when the prediction is closer to the roughness value of the test, it is necessary to build a model of surface roughness when considering the modulus of elasticity of the grinding wheel, the modulus of elasticity of machining materials as well as the characteristics of contact between grinding wheels and machining materials in each specific case.

\section{Building a Surface Roughness Model When Grinding C45 Steel with CBN Grinding Wheel}

C45 steel is considered to be the most common steel in the machine-building industry, with good work prices and low costs. The chemical composition and some properties of C45 steel are shown in Table 4 [15]. 
Table 2. Relationship between $\mathrm{CBN}$ wheel concentration and grain content [13]

\begin{tabular}{|c|c|c|c|c|c|c|c|c|}
\hline Concentration & 25 & 50 & 75 & 100 & 125 & 150 & 175 & 200 \\
\hline$v_{g}(\%)$ & 6.25 & 12.50 & 18.75 & 25.00 & 31.25 & 37.50 & 43.75 & 50.00 \\
\hline
\end{tabular}

Table 3. Materials - type of grinding wheel - suit able model [14]

\begin{tabular}{|c|c|c|l|}
\hline No. & Steel & Grinding wheel & \multicolumn{1}{|c|}{ Suitable model } \\
\hline 1 & SKD11 & CBN wheel (HY-100\#) & $R_{a}=0.92 * h_{m}$ \\
\hline 2 & SUJ2 & CBN wheel (HY-100\#) & $R_{a}=0.471 * h_{m}$ \\
\hline 3 & $3 X 13$ & CBN wheel (HY-100\#) & $R_{a}=0.471 * h_{m}$ \\
\hline 4 & C45 & CBN wheel (HY-100\#) & $R_{a}=0.92 * h_{m}$ \\
\hline 5 & SKD11 & Aluminum oxide wheel (36A60LV) & $R_{a}=0.37 * h_{m}$ \\
\hline 6 & SUJ2 & Aluminum oxide wheel (36A60LV) & $R_{a}=0.37 * h_{m}$ \\
\hline 7 & $3 X 13$ & Aluminum oxide wheel (36A60LV) & $R_{a}=0.37 * h_{m}$ \\
\hline 8 & C45 & Aluminum oxide wheel (36A60LV) & $R_{a}=0.471 * h_{m}$ \\
\hline
\end{tabular}

Table 4. Chemical composites and properties of C45 steel [15]

\begin{tabular}{|c|c|c|c|c|c|c|c|c|c|c|c|c|c|}
\hline \multicolumn{10}{|c|}{ Composite $(\%)$} & \multicolumn{5}{c|}{ Properties } \\
\hline $\mathrm{C}$ & $\mathrm{Si}$ & $\mathrm{Mn}$ & $\mathrm{Cr}$ & $\mathrm{Ni}$ & $\mathrm{Mo}$ & $\mathrm{V}$ & $\mathrm{Ti}$ & $\mathrm{B}$ & $\mathrm{Cu}$ & $\begin{array}{c}\text { modulus of } \\
\text { elasticity } \\
(\mathrm{GPa})\end{array}$ & $\begin{array}{c}\text { Poisson's } \\
\text { ratio }\end{array}$ & $\begin{array}{c}\text { Shear } \\
\text { module } \\
(\mathrm{Gpa})\end{array}$ & $\begin{array}{c}\text { Density } \\
\left(\mathrm{kg} / \mathrm{m}^{3}\right)\end{array}$ \\
\hline 0.44 & 0.23 & 0.65 & 0.15 & 0.15 & 0.04 & 0.01 & 0.001 & 0.0004 & 0.21 & 210 & 0.3 & 80 & 7800 \\
\hline
\end{tabular}

Among the grinding wheels, $\mathrm{CBN}$ grinding wheel is one of the best wheel. The use of CBN wheel allows machining of machine parts with very little roughness, which can reach several percent of micrometres. Another advantage of the CBN wheel is that it allows cutting at very high speeds, up to $200 \mathrm{~m} / \mathrm{s}$, which in turn allows for improved productivity. On the other hand, $\mathrm{CBN}$ wheel is the only type of wheel that can be use in dry grinding method, which is a distinctive feature of $\mathrm{CBN}$ wheel compared to convention wheel.

As analyzed above, in order to predict the surface roughness value as closely as possible during the test, the surface roughness model needs to be formulated as follows:

$$
R_{a}=0.92 *\left(E_{1} / E_{2}\right)^{n} * h_{m}
$$

In which, $E_{1}$ is the modulus of elasticity of grinding wheel; $\mathrm{E}_{2}$ is the modulus of elasticity of machining material; $\mathrm{n}$ is the exponent representing the contact characteris tic of the grinding wheel- workpiece. For CBN grinding wheel, because the thickness of the grain layer is only about $2 \mathrm{~mm}$, this value is very small when compared to the diameter of the grinding wheel hundreds of millimeters, so it can be considered the modulus of elasticity of the wheel to be the modulus of elasticity of the inner aluminum layer, approximately the value of 70GPa. The elastic modulus of C45 steel is approximately equal to 210GPa [15].

Thus, when grinding C45 steel with CBN grinding wheel, the roughness model is rewritten as follows:

$$
R_{a}=0.92 * 0.3574^{n} * h_{m}
$$

The coefficient $\mathrm{n}$ depends on the characteristics of contact between grinding wheel - workpiece, and specific machining conditions, the determination of the value of $n$ is often difficult. In this study, the value of $n$ was determined empirically when grinding C45 steel with CBN grinding wheel. The experiments were conducted on Toyoda (Taiwan) surface grinder - Figure 1. In each experiment, the value of the workpiece velocity $\left(\mathrm{v}_{\mathrm{w}}\right)$, cutting depth $(\mathrm{t})$ were changed. Meanwhile, the parameters that were fixed during the experiment were: grinding speed $26(\mathrm{~m} / \mathrm{s})$, depth of dressing $0.01(\mathrm{~mm})$, feed of dressing 150 (mm/min), using coolant oil as emulsion $10 \%$, flow irrigation 3.5 (litres/ min). C45 cylindrical steel specimens have the length size and size of diameter are $10 \mathrm{~mm}, 40 \mathrm{~mm}$ respectively (Figure 2); CBN grinding wheel (Korea), coded HY-180x 13x31.75-100 \# was used in this study (Figure 3). This wheel has a grain size of $M=100$, the symbol of the concentration of abrasive grains in the wheel is also valued at 100 , so according to Table $2, v_{g}=$ 25 (\%). The component is measured by roughness measuring machine SJ-210 (MITUTOYO - Japan) - Figure 4. The order of experiments is shown in Table 5. From there, the value of $\mathrm{n}$ is determined as shown in Table 5. The roughness value when predicting by model (5) is called $R_{a \text { (old) }}$, and the surface roughness value when predicting roughness according to model (12) is called $R_{a(p r e)}$, which also shown in Table 5 . 


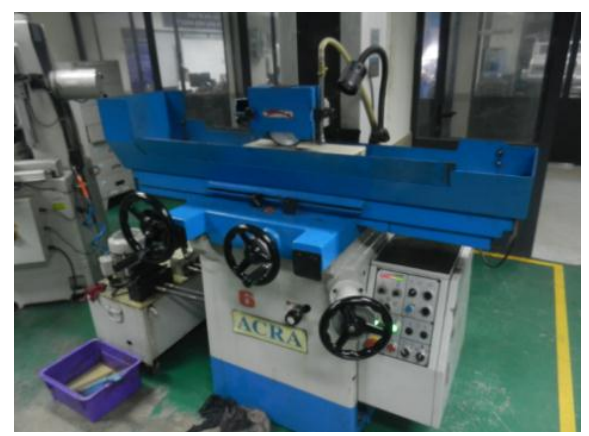

Figure 1. Surface grinder

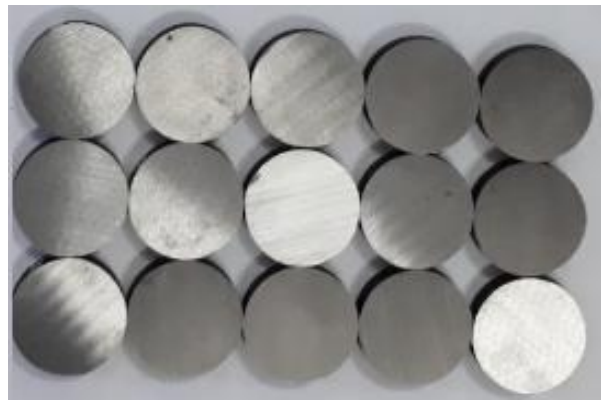

Figure 2. Components

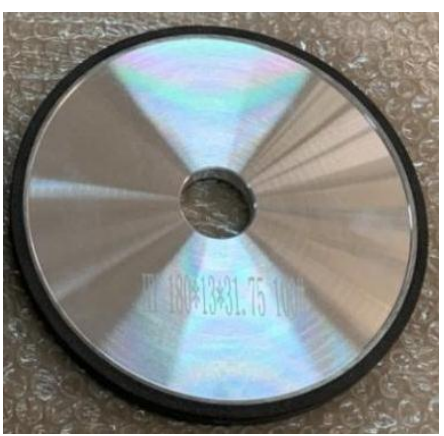

Figure 3. HY-180x13×31.75-100\# grinding wheel

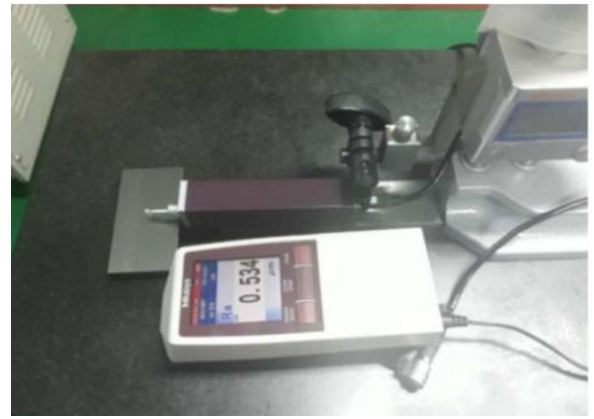

Figure 4. Surface roughness tester SJ-201

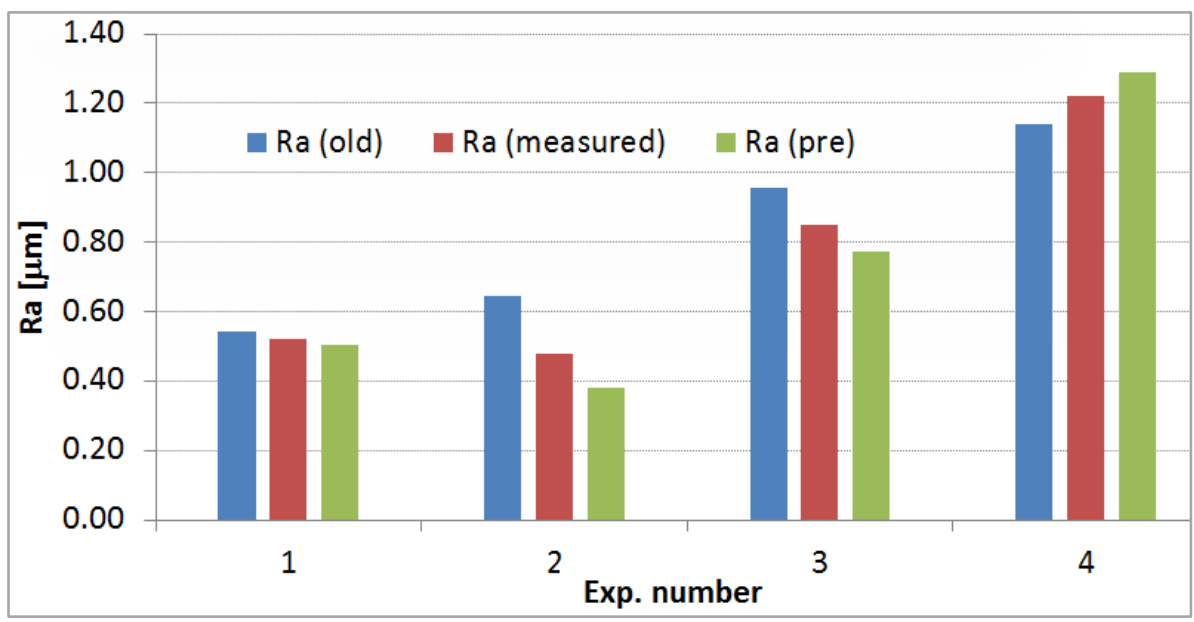

Figure 5. Surface roughness values when tested and predicted according to different models

Table 5. Surface roughness values when tested and predicted according to different models

\begin{tabular}{|c|c|c|c|c|c|c|c|c|}
\hline \multirow{2}{*}{ No. } & $v_{w}(\mathrm{~m} / \mathrm{min})$ & $t(\mathrm{~mm})$ & $R_{a(\text { measured })}$ & $\mathrm{n}$ & $R_{a(\text { old })}$ & $R_{a(\text { pre })}$ & \multicolumn{3}{|c|}{ Different $(\%)$} \\
\hline 1 & 5 & & & & & \\
\hline$a($ old $)$ & $R_{a(\text { pre })}$ \\
\hline 2 & 5 & 0.01 & 0.52 & 0.0401 & 0.54 & 0.50 & 4.21 & 3.28 \\
\hline 3 & 15 & 0.01 & 0.48 & 0.2863 & 0.64 & 0.38 & 34.26 & 21.19 \\
\hline 4 & 15 & 0.02 & 1.22 & -0.0666 & 1.14 & 1.29 & 6.62 & 5.69 \\
\hline \multicolumn{3}{|c|}{ Average } & & 0.0940 & & & 14.46 & 9.84 \\
\hline
\end{tabular}


A comparis on chart of surface roughnes suring the test, when predicted according to the model proposed in this study and according to the previous model is presented in Figure 5.

The data in Table 5 and the graph in Figure 5 show that the surface roughness model when considering additional parameters about the elastic modulus of the grinding wheel, the elastic modulus of materials and the characteristics of contact between grinding wheel with workpiece,... allow predicting roughness with less deviation than previous models. Specifically, in all four experiments conducted, the roughness value when predicted by the numerical model (12) was closer to the roughness value when tested than the roughness value when guessed from number (5) model. The difference between the roughness value predicted by this model has reduced the error from $14.46 \%$ to $9.84 \%$ compared to the previous model.

\section{Conclusions}

This research has inherited from the previous studies and developed them to build a model of surface roughness of workpiece in grinding. Many parameters that have a great influence on the surface roughness are taken into consideration when building the roughness model, such as the cutting parameters, the characteristics of the grinding wheel, the elastic modulus of the material, ect. The built model that can predict surface roughness when grinding with errors compared to the experimental results is very small (less than 10\%). Using this model allows selection and control of the processing to process the surface of the part with small roughness, allowing to reduce the time to adjust the machine, test machining time, contributing to improving the efficiency of grinding process.

The research method presented in this paper is not only applied when grinding C45 steel with CBN grinding wheel, but can also be applied to model surface roughness under different conditions.

In order to predict the roughness value when the prediction is closer to the roughness value of the test, it is necessary to include the roughness model with parameters that have a lot of influence on the roughness such as dressing parameters, lubrication - cooling parameters, hardness and the modulus of elasticity of materials, hardness of grinding wheel, ect. This is also the development direction for the next research.

\section{Acknowledgements}

The authors appreciate the funding from Hanoi University of Industry, Vietnam. This research is funded by Hanoi University of Industry under grant number 12-2019RD/HĐ-ĐHCN.

\section{REFERENCES}

[1] Stephen Malkin, ChangshengGuo, (2008), Grinding technology - Theory and application of machining with abrasives (Second edition), Industrial press, New York.

[2] Marinescu Loan D, EckartUhlmann and Brian Rowe W, (2006), Handbook of machining with grinding wheels, CRC Press Taylor \& Francis Group.

[3] Rogelio L. Hecker, Steven Y. Liang (2003), Predictive modeling of surface roughness in grinding, International Journal of Machine Tools an dManufacture, 43, pp.755-761.

[4] Sanchit Kumar Khare, Sanjay Agarwa (2015), Predictive modeling of surface roughness in grinding, 15th CIRP Conference on Modelling of Machining Operations, Procedia CIRP,31, pp.375-380

[5] Sanjay Agarwal, P. Venkateswara Rao (2005), Surfacce roughness prediction model for ceramic grinding, ASME International Mechanical Engineering Congress and Exposition, Orlando, Florida USA, pp.1-9.

[6] Sanchit Kumar Khare and Sanjay Agarwal (2015), Predictive modeling of surface roughness in grinding, Procedia CIRP,31, pp.375-380.

[7] Krishna Kumar Saxena, Sanjay Agarwal (2016), Surface Roughness Prediction in Grinding: A Probabilistic Approach, MATEC Web of Conferences,82, 01019, pp.1-9.

[8] Anne Venu Gopal, P. Venkateswara Rao (2004), A new chip-thickness model for performance assessment of silicon carbide grinding. Int $\mathbf{J}$ Adv Manuf Technol, Vol. 24, pp. 816-820

[9] J. E. Mayer. G.P. Fang (1994), Effect of grit depth of cut on strength of ground ceramics, Annals CIRP, Vol. 43, pp. 309312 .

[10] S. Somasundaram. C. Thiagarajan (2013), Experimental Evaluation of a Chip Thickness Model Based on the Fracture Toughness of Abrasive and Work Material in Grinding of Alumina Ceramics, International Journal of Modern Engineering Research, Vol. 3. Issue. 6, pp.38253829.

[11] Xu. Hockin, S. Jahanmir, L. K. Ives (1997), Effect of grinding on strength of tetragonal zirconia and zirconiatoughned alumina's, Journal of Machining Science Technology, Vol. 1, pp. 49-66

[12] Do Duc Trung, Nguyen Van Thien, Hoang Tien Dung, (2017), Predictive Surface Roughness of Workpiece in Surface Grinding, American Association for Science and Technology, Vol. 4, No. 6, pp.37-41.

[13] https://www.noritake.co.jp/eng/catalog_ty pe/download/8aa 6080c86465c93cfebd53c07689c7f.pdf

[14] Do Duc Trung, Nguyen Hong Son (2019), An experimental study on prediction of surface roughness in grinding, International Journal of Mechanical and Production Engineering Research and Development, Vol. 10, No. 1, pp. 47-58 